\title{
The AMINO experiment: methane photolysis under Solar VUV irradiation on the EXPOSE-R facility of the International Space Station
}

\author{
Nathalie Carrasco ${ }^{1,2}$, Hervé Cottin ${ }^{3}$, Mégane Cloix ${ }^{3}$, Murielle Jérome ${ }^{3}$, Yves Bénilan ${ }^{3}$, \\ Patrice Coll ${ }^{2,3}$, Marie-Claire Gazeau ${ }^{3}$, François Raulin ${ }^{3}$, Kafila Saiagh $^{3}$, Didier Chaput ${ }^{4}$ \\ and Cyril Szopa' \\ ${ }^{1}$ Université Versailles St-Quentin, UPMC University Paris 06, CNRS, LATMOS, 11 blvd d'Alembert, 78280 Guyancourt, \\ France \\ e-mail: nathalie.carrasco@latmos.ipsl.fr \\ ${ }^{2}$ Institut Universitaire de France, 103 blv St-Michel, 75005 Paris, France \\ ${ }^{3}$ Laboratoire Interuniversitaire des Systèmes Atmosphériques, LISA, UMR CNRS 7583, Université Paris Est \\ Créteil and Université Paris Diderot, Institut Pierre Simon Laplace, 61 Avenue du Général De Gaulle, \\ 94010 Créteil Cedex, France \\ ${ }^{4}$ Centre National d'Etudes Spatiales, Toulouse, France
}

\begin{abstract}
The scientific aim of the present campaign is to study the whole chain of methane photo-degradation, as initiated by Solar vacuum-ultraviolet irradiation in Titan's atmosphere. For this purpose, the AMINO experiment on the EXPOSE-R mission has loaded closed cells for gas-phase photochemistry in space conditions. Two different gas mixtures have been exposed, named Titan 1 and Titan 2, involving both $\mathrm{N}_{2}-\mathrm{CH}_{4}$ gas mixtures, without and with $\mathrm{CO}_{2}$, respectively. $\mathrm{CO}_{2}$ is added as a source of reactive oxygen in the cells. The cell contents were analysed thanks to infrared absorption spectroscopy, gas chromatography and mass spectrometry. Methane consumption leads to the formation of saturated hydrocarbons, with no detectable influence of $\mathrm{CO}_{2}$. This successful campaign provides a first benchmark for characterizing the whole methane photochemical system in space conditions. A thin film of tholin-like compounds appears to form on the cell walls of the exposed cells.

Received 7 April 2014, accepted 11 June 2014, first published online 18 July 2014
\end{abstract}

Key words: atmospheric chemistry, planetary sciences, Titan.

\section{Introduction}

\section{Methane in the outer Solar system}

Methane is the most abundant hydrocarbon of the reducing atmospheres found beyond the asteroid belt in the Solar system body. Its mole fraction reaches several $10^{-3}$ in Jupiter and Saturn atmosphere, and several $10^{-2}$ in the atmosphere of Uranus and Neptune (Encrenaz 2005). But most of all, methane contributes for several percent to the dense atmosphere enveloping Titan. One of the main planetary interests of this specific molecule is its photolysis which appears as a source of larger hydrocarbons in planetary atmospheres and drives the organic growth in those environments (Raulin \& Bruston 1996).

\section{Knowledge about methane photoproducts: the Lyman- $\alpha$ supremacy}

This robust molecule requires vacuum-ultraviolet (VUV) radiation to be photo-dissociated. Considering the major absorption of nitrogen for wavelength lower than $100 \mathrm{~nm}$, the convolution of the methane photoabsorption cross section and the Solar spectrum contributes to about $70 \%$ of methane photo-dissociation by the only Lyman- $\alpha$ wavelength on the top of methane-rich atmospheres such as Titan (Gans et al. 2013).

An extensive work has been made to characterize methane photoproducts at Lyman- $\alpha$ (Romanzin et al. 2008; Gans et al. 2010) and references therein). The branching ratios for methane photolysis are now known with a good precision at this wavelength, showing a balanced production of $\mathrm{CH}_{3}$ and $\mathrm{CH}_{2}$. However, branching ratios out of Lyman- $\alpha$ remain mostly unknown, except at a few given wavelengths: one study at $118 \mathrm{~nm}$ (Gans et al. 2010) and one at $106 \mathrm{~nm}$ (Rebbert \& Ausloos 1972). We are far from knowing methane photolysis branching ratios on the whole Solar wavelength range.

The work of (Gans et al. 2013) models methane branching ratios on the whole VUV domain, but with large indeterminations on branching ratios at wavelengths larger than Lyman- $\alpha$ considering the absence of experimental data in this range. Such uncertainties are an issue for Titan's photochemical modelling. The $130-150 \mathrm{~nm}$ wavelength range is indeed identified as important for methane photolysis in Titan stratosphere between 400 and $700 \mathrm{~km}$ of altitude. 
Irradiating methane under realistic Solar VUV conditions with experiments in orbit

To address this lack of knowledge on the fate of methane by photolysis on the whole VUV Solar spectrum, a first experiment has been led in orbit during the EXPOSE-PROCESS experiment (Cottin et al. 2012). $\mathrm{CH}_{4} / \mathrm{Ar}$ and $\mathrm{CH}_{4} / \mathrm{N}_{2}$ gas mixtures were exposed for approximately $\sim 1300 \mathrm{~h}$ to the Sun irradiation in photochemical cells onboard the International Space Station (ISS). The aim of these first experiments was to trigger methane photolysis with the full Solar spectrum (including Lyman- $\alpha$ wavelength). This previous promising experiment showed significant productions of saturated hydrocarbons photoproducts: $\mathrm{C}_{2} \mathrm{H}_{6}, \mathrm{C}_{3} \mathrm{H}_{8}, \mathrm{C}_{4} \mathrm{H}_{10}$ and $\mathrm{C}_{5} \mathrm{H}_{12}$. However, no $\mathrm{C}_{2} \mathrm{H}_{2}$ or $\mathrm{C}_{2} \mathrm{H}_{4}$ production could be detected. Unfortunately, the EXPOSE-PROCESS cells suffered from contamination issues and severe leaks preventing any quantification. A new set of photochemical cells has therefore been boarded in the EXPOSE-R/AMINO experiment. The objectives are to complete the sparse experimental knowledge on methane photolysis, with a direct measurement of the cumulated effects of the whole Solar spectrum above $115 \mathrm{~nm}$ (cut of the $\mathrm{MgF}_{2}$ windows) and the whole chemical chain initiated by methane photolysis including the chemistry of the photoproducts.

\section{Materials and methods}

The AMINO experiment was part of the EXPOSE-R campaign outside the Russian module Zvezda of the ISS. EXPOSE-R is a passive exposure facility with AMINO as one of the chemical experiments selected by ESA (Rabbow et al. 2014). The EXPOSE-R samples were outside the ISS from 10 March 2009 to 28 January 2011, i.e. 682 days. AMINO was a set of 30 solid and gaseous phase samples exposed to space environment (with additional flight and ground controls) in so called 'open' and 'closed cells'. Details and results about 'open' cells, i.e. with direct venting to space are reported in (Bertrand et al. Submitted; Vergne et al. Submitted). This paper is specifically focused on closed cells, i. e. small sealed chambers for conducting experiments with samples in the gaseous phase.

Such closed cells have already been used in the UVolution (BIOPAN 6) (Cottin et al. 2008) and PROCESS (EXPOSE-E) (Cottin et al. 2012) experiments. Although the concept is the same since 2007, the manufacturing process has drastically changed since their first use in UVolution and PROCESS. The first generation of closed cells was made of two aluminium cylinders which where screwed one into the other. A $\mathrm{MgF} 2$ window was glued at each end of the cell (transparent from $115 \mathrm{~nm}$ in the VUV to $10 \mu \mathrm{m}$ in the mid infrared (IR)). Tightness was ensured by a Viton O-ring between the two parts. The two parts of the cell were screwed one into the other in a controlled atmosphere with the composition intended to be the actual gaseous sample. It has been shown that, although the level of vacuum-tightness is sufficient for short duration experiments such as UVolution (14 days in space, and roughly one month between the preparation of the samples and their analysis after return), it is not enough for long duration experiments such as the ones conducted outside of the space station. Some of the PROCESS closed cells were empty when they returned to Earth.

\section{Cells}

A new generation of closed cells has been manufactured for AMINO, under the supervision Air Liquide (DTA Grenoble, France). This time the body of the cell is made of stainless steel, the windows are brazed and the vacuum-tightness between the two parts of the cells is ensured by laser welding. This results in a leak level below $10-10 \mathrm{mb} \mathrm{L} \mathrm{s}^{-1}$, compatible with longduration experiments in orbit (loss $<10 \%$ for 2 years in space) (Fig. 1).

The internal volume is of $0.274 \mathrm{~cm}^{3}$. The VUV transmission function of the windows was not determined systematically but on a few windows. A typical transmission spectrum is given in Fig. 2.

\section{Samples}

The gas mixtures were injected in the cells at a total gas pressure of $1.5 \times 10^{5} \mathrm{~Pa}$, to ensure that no contamination would enter the cells during their preparation. Two gas mixtures were prepared, named Titan 1 and Titan 2, and described in Table 1. Those are based on $\mathrm{N}_{2}-\mathrm{CH}_{4}$ gas mixtures as in Titan's atmosphere, but with a methane mole fraction one order of magnitude larger to improve the detection and quantification of methane photoproducts. Titan 1 experiment aimed at studying the methane photolytic chain, whereas Titan 2 added the contribution of active oxygen to the system, as $\mathrm{CO}_{2}$ is efficiently photolysed in the Solar VUV range transmitted by the $\mathrm{MgF}_{2}$ windows (Yoshino et al. 1996; Venot et al. 2013). Finally, helium has been added as a non-reactive gas to ensure the total pressure higher than ambient.

\section{Irradiation conditions}

Similarly to the EXPOSE-PROCESS experiment, two cells per scientific case were exposed during the flight, and the same number of control cells was arranged below the exposed layer. This doubling ensures the reproducibility of the experiment. Additional reference cells were moreover kept on the ground at the DLR-Cologne (German Aerospace Center), either under vacuum and a $278 \mathrm{~K}$ controlled temperature, or under vacuum, submitted to the same temperature cycle as the samples onboard the ISS.

The flight in orbit lasted 2 years, but the effective irradiation time of the exposed cells was significantly lower. During the whole exposure period, temperature of the sample carriers was both measured and simulated. The average experiment temperature was $292 \mathrm{~K}$ with maximum and minimum of $319 \mathrm{~K}$ and $246 \mathrm{~K}$ respectively. No effect from cosmic radiation has been demonstrated in our results (information derived from the flight controls samples (exposed to radiation but not to UV) which showed no measurable changes). Exposure of samples to Sun light is estimated to $2946 \mathrm{~h}$ of equivalent perpendicular Solar irradiation (Beuselinck \& Van Bavinchove 2011). 

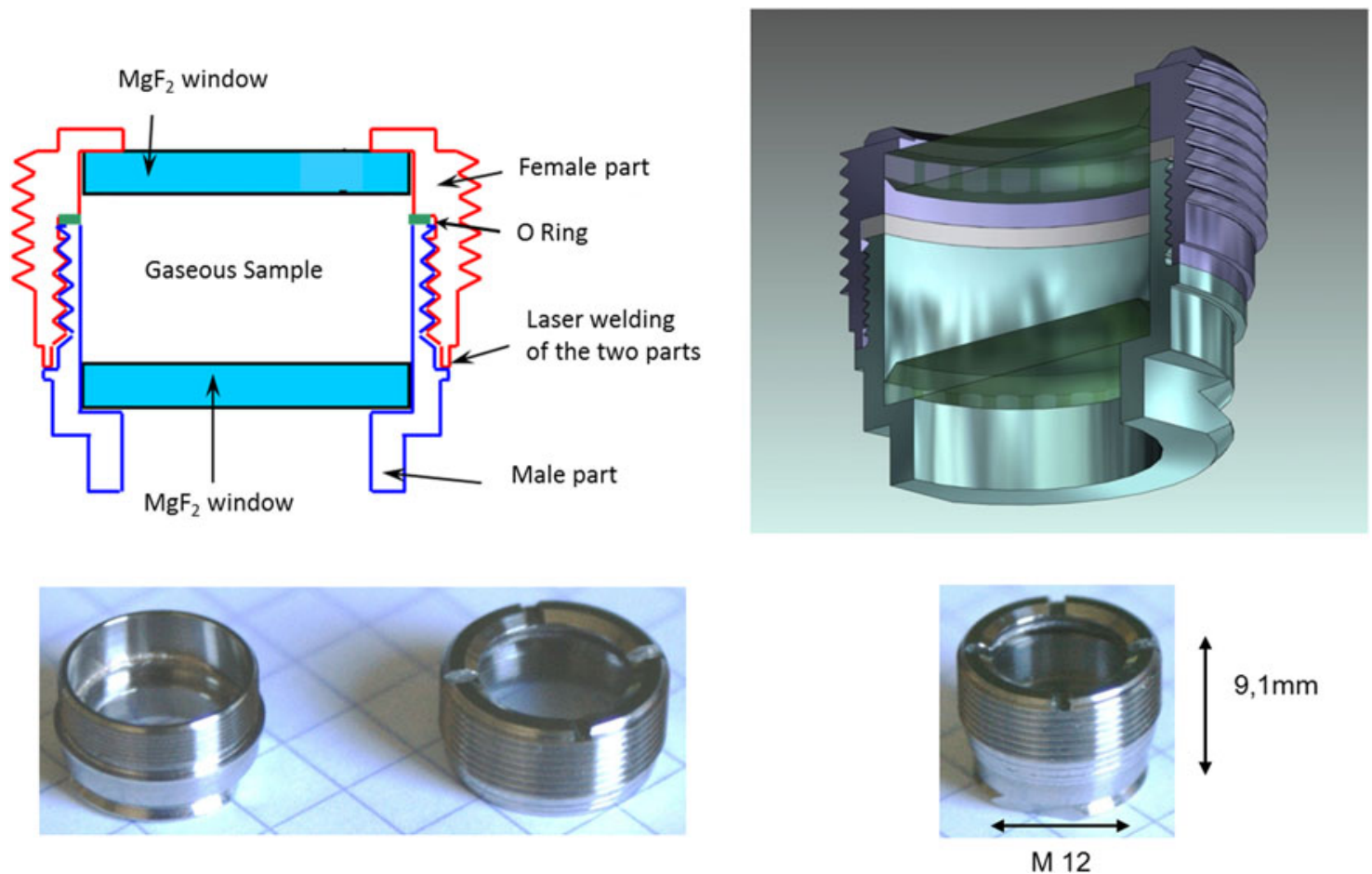

Fig. 1. AMINO closed cells. Two stainless steel cylinders are screwed into each other in a controlled atmosphere with the composition intended to be the actual gaseous sample. Two MgF2 (transparent from $115 \mathrm{~nm}$ in the VUV to $10 \mu \mathrm{m}$ in the mid IR) are brazed at both ends to allow photolysis in the VUV-UV and the analysis of molecules inside the cell by spectroscopy. Sealing (relative to lab atmosphere or vacuum in space) is ensured by a Viton O-ring and laser welding.

Total UV irradiance $(100-400 \mathrm{~nm})$ at the sample site for AMINO is $1.043 \times 10^{3} \mathrm{MJ} \mathrm{m}^{-2}$ (Beuselinck \& Van Bavinchove 2011).

\section{Diagnosis}

\section{IR absorption spectroscopy}

Measurements were made through the windows in the closed cells by an FTIR spectrometer (Bruker Optic, Vertex 70). Data acquisition was performed using OPUS 6.5 software. Spectra were obtained with a $4 \mathrm{~cm}^{-1}$ resolution and the acquisition of 32 scans.

\section{Gas chromatography (GC)-mass spectrometry (MS)}

Once the windows of the closed cell were broken, their content was released into the analytical cell. Then the gaseous samples were transferred thanks to a sealed syringe for analysis by GC (VARIAN CP 3800) coupled to MS (VARIAN Saturn 2200), with an $\mathrm{RT}^{\mathbb{R}}$-Q-BOND GC column (length: $30 \mathrm{~m}$, internal diameter: $0.25 \mathrm{~mm}$ and film thickness: $8 \mu \mathrm{m})$. Temperature programme was $238 \mathrm{~K}$ during $2 \mathrm{~min}$, rose at $10 \mathrm{~K} \mathrm{~min}^{-1}$ up to $473 \mathrm{~K}$, and then stayed at $473 \mathrm{~K}$ during $60 \mathrm{~min}$. Pressure was set from $0.45 \times 10^{5}$ to $1.24 \times 10^{5} \mathrm{~Pa}$ at $0.10 \times 10^{5} \mathrm{~Pa} \mathrm{~min}^{-1}$, and then kept at $1.24 \times 10^{5} \mathrm{~Pa}$ during $60 \mathrm{~min}$. This method was optimized for the analysis of small hydrocarbons. Compounds were identified in two ways as follows: (1) by comparing their retention time to that of known standards and (2) by their mass spectrum obtained by electron impact ionization at $70 \mathrm{eV}$.
Quantification of the compounds was achieved with calibration curves for each molecule.

\section{Results}

\section{Methane photolysis}

With the new cells sealing system, gas losses were expected to be lower than with the previous PROCESS experiment. These possible losses are evaluated by comparing the IR absorption signatures of the non-irradiated cells before and after the flight duration. The methane absorption structure in the $1200-1400 \mathrm{~cm}^{-1}$ wavenumber range is chosen to quantify the evolution of the methane signature as it is not saturated contrary to the second main methane structure at $\sim 3000 \mathrm{~cm}^{-1}$.

The peak area of this methane structure is given in Table 2 for all Titan cells onboard the AMINO experiment. The losses observed for the methane signature are similar in the four nonexposed cells, and are as high as $(9 \pm 2) \%$ (average value and standard deviation for the four cells). This is a clear improvement compared to the PROCESS cells, where the losses varied from a cell to another between 5 up to $100 \%$ (Cottin et al. 2012). The value is also in agreement with the expectancies of less than $10 \%$ for 2 years in space as described in (Cottin et al. 2012).

A similar analysis of the evolution of the methane structure in the $1187-1410 \mathrm{~cm}^{-1}$ range is made on the irradiated cells (Table 2). A higher variation is observed compared to the non-irradiated cells, with a decrease of the methane signature 


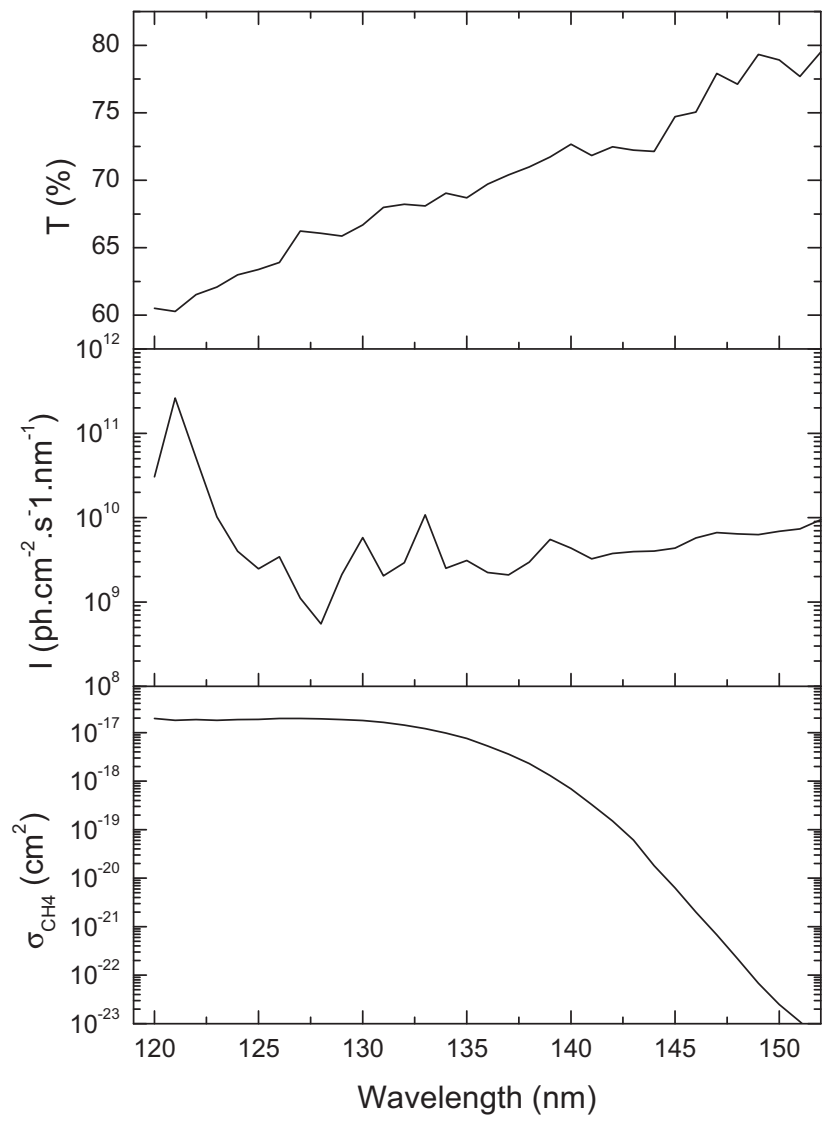

Fig. 2. (Top) VUV transmission function of a typical window on the AMINO-PROCESS gas cells. (Middle) Solar flux at 1 AU, I $\left(\mathrm{ph} \mathrm{cm}^{-2} \mathrm{~s}^{-1} \mathrm{~nm}^{-1}\right.$ ) adapted from (Thuillier et al. 2004) and corresponding to the flux before crossing the cells' magnesium fluoride windows. (Bottom) Methane absorption cross section, $\sigma_{\mathrm{CH} 4}\left(\mathrm{~cm}^{2}\right)$ (Chen \& Wu 2004).

of $31 \pm 4 \%$ (Fig. 3). This higher decrease cannot be directly assigned to methane photolysis in the irradiated cells as possible higher leaks on the exposed ISS accommodation could also occur considering the external location.

To clarify this point, a measurement of the pressure in the cells was made after the flight for GC-MS further analysis purpose. Cells were opened and the gas content was expanded in a higher volume by a factor of $\sim 20$ leading to pressures $(\mathrm{P} 1)$ that are reported in Table 3 . The cross comparison of the pressures obtained in the irradiated versus non-irradiated cells shows no additional gas loss in the irradiated cells. The irradiated cells were therefore not exposed to higher leaks than the control ones.

The $31 \pm 4 \%$ methane decrease observed in the irradiated cells before and after the flight can therefore approximately be allocated to leaks during the flight for about $9 \%$ of and to methane consumption by photolysis for $22 \%$. Moreover, no difference on the methane photolysis could be observed in the presence or in the absence of $\mathrm{CO}_{2}$ (comparison of Titan 1 and 2 cells).

The theoretical methane consumption is moreover calculated by convolution of the Solar spectrum $I(\lambda)$, the
Table 1. Composition of the gas mixtures injected in the cells

\begin{tabular}{lll}
\hline & Species & Gas mixtures (\%) \\
\hline Titan 1 & $\mathrm{CH}_{4}-\mathrm{N}_{2}-\mathrm{He}$ & $33.3-53.3-13.3$ \\
Titan 2 & $\mathrm{CH}_{4}-\mathrm{N}_{2}-\mathrm{CO}_{2}-\mathrm{He}$ & $33.3-46.7-6.7-13.3$ \\
\hline
\end{tabular}

transmission function of the windows $T(\lambda)$, the methane absorption cross section $\sigma(\lambda)$ (all shown in Fig. 1), integrated on the photolysis duration.

$$
\frac{\left(\mathrm{CH}_{4}\right)_{f}}{\left(\mathrm{CH}_{4}\right)_{f_{0}}}=\exp (-J \times \Delta t),
$$

with $J=\int_{115}^{200} I(\lambda) \sigma(\lambda) T(\lambda) \mathrm{d} \lambda, J$ is the methane photolysis constant with the ISS conditions through the $\mathrm{MgF}_{2}$ windows ( $\lambda$ values above $115 \mathrm{~nm}$ ), and $\Delta t$ the exposure duration.

After $\Delta t=2946 \mathrm{~h}$, the remaining methane should be negligible (theoretical ratio of $\sim 10^{-19}$ ). The explanation for such a discrepancy is discussed later.

\section{A thin-film formation on the window cells}

Some IR signatures of products are found after subtraction of the methane contribution in the spectra of the irradiated cells. The so-called residue of experiment Titan 1 is shown in the bottom of Fig. 4. The subtraction of the methane structure at $\sim 3000 \mathrm{~cm}^{-1}$ is made difficult because of the saturation of this signature in the spectrum. Nevertheless, several features appear at about 1600, 2850, 2920 and $3070 \mathrm{~cm}^{-1}$ and one large absorption band centred at $\sim 3400 \mathrm{~cm}^{-1}$. The residue of Titan 2 experiment shows the same signatures at 2850 and $2920 \mathrm{~cm}^{-1}$ but is noisier, and the bands at 1600 and $3070 \mathrm{~cm}^{-1}$ are less pronounced.

As $\mathrm{C}_{2} \mathrm{H}_{6}$ was the most abundant photochemical product detected in the previous PROCESS experiment (Cottin et al. 2012), its spectrum is stacked on the top of Fig. 3. We can suspect that this hydrocarbon could participate to the residue absorption observed in the aliphatic $2850-3100 \mathrm{~cm}^{-1}$ wavenumber range. However, no $\mathrm{C}_{2} \mathrm{H}_{6}$ line could explain the broad feature at $3400 \mathrm{~cm}^{-1}$ and the one at $1600 \mathrm{~cm}^{-1}$.

Such large signatures are actually consistent with the presence of an organic film produced on the internal side of the $\mathrm{MgF}_{2}$ window of the irradiated cells, as suggested by the similarity with the overlaid spectrum of a carbonitride thin film produced in a plasma reactor simulating Titan's atmospheric chemistry (Titan's tholins) (Gautier et al. 2012). A difference can however be noticed with the absence of nitrile and isonitrile signature (2200 and $2350 \mathrm{~cm}^{-1}$ wavenumber range) in the film compared to Titan's tholins.

The high wavenumber value of the $\mathrm{C}-\mathrm{H}$ bonds signature at $3070 \mathrm{~cm}^{-1}$ suggests a contribution of aromatic rings in the film. Moreover, the broad signature centred at $3400 \mathrm{~cm}^{-1}$ is consistent with $\mathrm{N}-\mathrm{H}$ amine bonds in the organic solid deposit. The nitrogen incorporation in the films is surprising as $\mathrm{MgF}_{2}$ windows prevent any direct photo-dissociation of molecular nitrogen in the cells. However, nitrogen enrichment in the solid photochemical products of $\mathrm{N}_{2}-\mathrm{CH}_{4}$ irradiated mixtures has previously been reported in photochemical cells at 600 torr 
Table 2. Methane absorption band area in the $1187-1410 \mathrm{~cm}^{-1}$ wavenumber range before and after the flight

\begin{tabular}{llllr}
\hline Type & Non-irradiated cells & Area before & Area after & Variation (\%) \\
\hline Titan 1 & CF 011 & 29.1 & 26.6 & 8.4 \\
Titan 1 & CF 024 & 22.6 & 21.1 & 6.4 \\
Titan 2 & CF 023 & 26.0 & 23.3 & 10.5 \\
Titan 2 & CF 039 & 26.7 & 24.2 & 9.4 \\
Type & Irradiated cells & Area before & Area after & Variation (\%) \\
\hline Titan 1 & CF 020 & 30.1 & 20.6 & 31.6 \\
Titan 1 & CF 041 & 29.4 & 21.7 & 26.1 \\
Titan 2 & CF 019 & 26.9 & 17.6 & 34.5 \\
Titan 2 & CF 014 & 26.8 & 18.0 & 32.6 \\
\hline
\end{tabular}

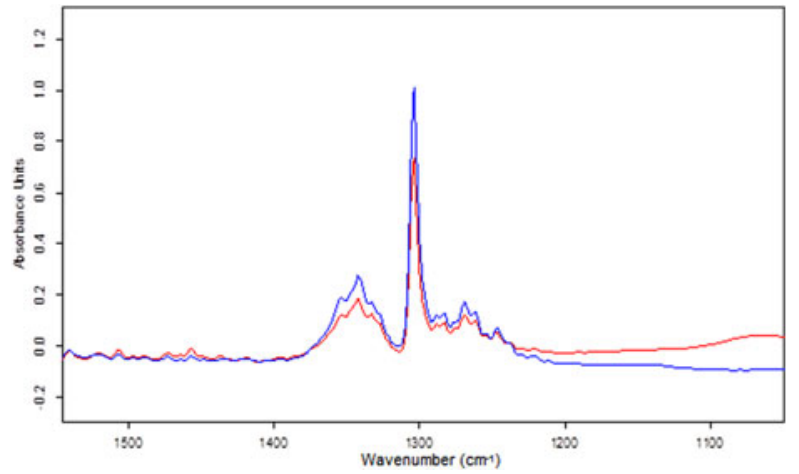

Fig. 3. Spectra in cell CF 020 (irradiated case) before (blue) and after (red) the flight in the $1200-1400 \mathrm{~cm}^{-1}$ wavenumber range.

pressure irradiated with Lyman- $\alpha$ lamps (Trainer et al. 2012). The process remains unclear, but could be related to the three body addition involving $\mathrm{CH}$ radicals: $\mathrm{N}_{2}+\mathrm{CH}+\mathrm{M}$, known to be exothermic and possibly barrier-less.

As illustrated in Fig. 5, no $\mathrm{CO}_{2}$ consumption is observed by comparing the $\mathrm{CO}_{2}$ peak areas in the $2200-2500 \mathrm{~cm}^{-1}$ range in both irradiated and non-irradiated cells (the area is found even higher in the exposed cell). This absence of consumption compared to methane is explained by the lower photolysis rate constant for $\mathrm{CO}_{2}$ resulting from the lower absorption cross section at Lyman- $\alpha$ convoluted by the sharp decrease of the VUV Solar flux outside Lyman- $\alpha$.

\section{Gas-phase product analysis by $G C-M S$}

Chromatograms (total ion current) of the four representative cases are compared on Fig. 6: irradiated and non-irradiated cells in the Titan 1 case, and irradiated and non-irradiated cells in the Titan 2 case.

The chromatograms reveal five peaks specific to irradiated gas mixtures. Those are identified through their retention time (Table 4) and MS fragmentation pattern at $70 \mathrm{eV}$. In order to compare the production in the different irradiated cells, chromatogram peak areas are normalized by the pressure $\mathrm{P} 2$ of the GC-MS injections (Table 3).

First of all, no noticeable difference can be found between Titan 1 and 2 cases: the detected species are the same, with similar products and similar peak areas. This result is not
Table 3 P1: Final pressure measured in the cells after their aperture and expansion by a factor of 20. P2: pressure of the sample injected in the GC-MS, deducted by a syringe

\begin{tabular}{llcl}
\hline Cell name & Exposure conditions & P1 (hPa) & P2 (hPa) \\
\hline Titan1 CF020 & Irradiated & 82 & 37 \\
Titan1 CF041 & Irradiated & 87 & 42 \\
Titan1 CF011 & Non-irradiated & 86 & 39 \\
Titan1 CF024 & Non-irradiated & 69 & 31 \\
Titan2 CF019 & Irradiated & 117 & 50 \\
Titan2 CF014 & Irradiated & 105 & 46 \\
Titan2 CF023 & Non-irradiated & 84 & 41 \\
Titan2 CF039 & Non-irradiated & 82 & 40 \\
\hline
\end{tabular}

surprising as similar $\mathrm{CH}_{4}$ consumptions and no- $\mathrm{CO}_{2}$ consumptions are observed in the presence of $\mathrm{CO}_{2}$. We can therefore consider these four cell results as equivalent for the further data treatment.

Concerning the five products detected only in the irradiated cases, those are all saturated hydrocarbon: $\mathrm{C}_{2} \mathrm{H}_{6}, \mathrm{C}_{3} \mathrm{H}_{8}$, $\mathrm{C}_{4} \mathrm{H}_{10}$, isobutane and $n$-pentane $\mathrm{C}_{5} \mathrm{H}_{12}$. In order to confirm this observation, unsaturated species are specifically scrutinized in all collected cells, even in the reference cells kept on the ground (non-irradiated samples kept on the ground under vacuum at a $278 \mathrm{~K}$ controlled temperature and samples submitted to the same thermal cycling as in space, at the DLRCologne). Unsaturated species were chosen on the criterion of their detection in Titan's atmosphere: $\mathrm{C}_{2} \mathrm{H}_{2}, \mathrm{C}_{2} \mathrm{H}_{4}$ and $\mathrm{C}_{6} \mathrm{H}_{6}$ (Waite et al. 2005; Coustenis et al. 2007; Teanby et al. 2007; Vinatier et al. 2010). First, if present, $\mathrm{C}_{2} \mathrm{H}_{2}$ concentration is below the detection limits of the GC-MS and is not detected in any cell. Then, $\mathrm{C}_{2} \mathrm{H}_{4}$ and $\mathrm{C}_{6} \mathrm{H}_{6}$ are detected in significant amounts and their TIC peak areas per pressure unit are reported in Fig. 7. Nevertheless, the comparison between the irradiated cells and the reference cases confirms that no significant production of $\mathrm{C}_{2} \mathrm{H}_{4}$ and $\mathrm{C}_{6} \mathrm{H}_{6}$ can be observed in the irradiated cells. There is therefore no significant production of unsaturated molecules in the AMINO-cells, contrarily to Titan's atmosphere. This disagreement is explained by the higher pressure used in the AMINO-cells compared to Titan's stratosphere and ionosphere. Indeed a higher pressure increases the rate of the termolecular processes, favouring the formation of saturated molecules (Peng et al. 2014). 

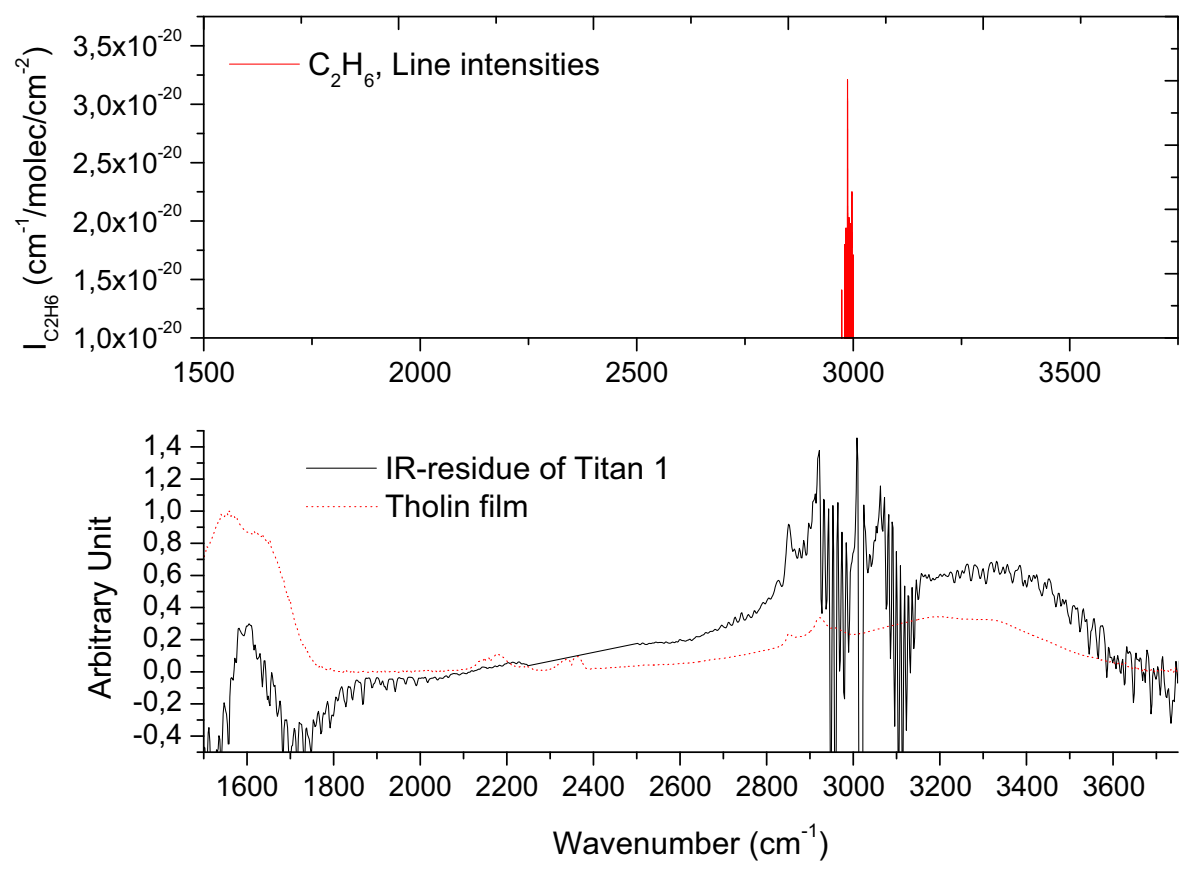

Fig. 4. (Top) Geisa reference spectra for $\mathrm{C}_{2} \mathrm{H}_{6}$ (Jacquinet-Husson et al. 2011). (Bottom) In black, residue of the Titan 1 experiments: normalized absorbance spectra of the irradiated cell after subtraction of the methane absorption contribution. In red, spectrum of a thin carbonitride films produced in a $\mathrm{N}_{2}-\mathrm{CH}_{4}$ plasma discharge (Titan's tholins) (Gautier et al. 2012).

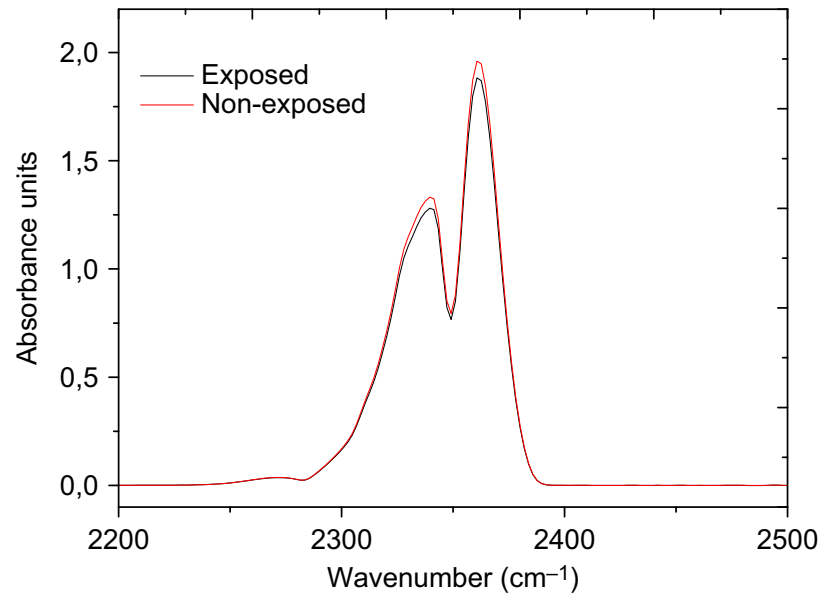

Fig. 5. Absorbance spectra of the Titan 2 experiments after flight focused on the $\mathrm{CO}_{2}$ absorption bands in the $2200-2500 \mathrm{~cm}^{-1}$ range.

The clear signatures of the five saturated species in the only irradiated cells enable their relative quantification. The TIC peak areas in the chromatogram are related to the concentration of the species through the ionization cross section by electron impact at $70 \mathrm{eV}$. Experimental data for such a cross section are available for ethane, propane (Nishimura \& Tawara 1994) and butane (Jiao et al. 2007), but not pentane. Models (Fitch \& Sauter 1983; Hwang et al. 1996) have been developed to approximate these total cross sections. The model of Hwang et al. (1996) is recommended by the NIST and leads to underestimated values for the two first species by less than $15 \%$. The simple empirical model by Fitch \& Sauter (1983) calculates ionization cross sections for even larger hydrocarbons, including pentane: the comparison with experimental values show in this case a systematic overestimation by less than $15 \%$ for $\mathrm{C}_{2} \mathrm{H}_{6}, \mathrm{C}_{3} \mathrm{H}_{8}$ and $\mathrm{C}_{4} \mathrm{H}_{10}$ (Table 5).

For consistency, the electron impact ionization cross sections at $70 \mathrm{eV}$ are estimated with the model of Fitch and Sauter. Peak areas per pressure unit are corrected by the ionization cross sections, providing a rough approximation of the hydrocarbon concentrations (neglecting the transmission function of the GC-MS instrument). Then concentrations are normalized in Fig. 8 by the $\mathrm{C}_{2} \mathrm{H}_{6}$ value in order to show relative abundances between hydrocarbons. The total $\mathrm{C}_{4} \mathrm{H}_{10}$ concentration is obtained by addition of the two isomers contributions, $n$-butane and 2-methylpropane. A quantitative trend in-between the detected saturated products can then be roughly calculated: when increasing the hydrocarbon by one $\mathrm{CH}_{2}$ unit, the concentration of the larger $\mathrm{HC}$ is divided by about a factor of five. As already underlined in (Cottin et al. 2012), no quantitative comparison with photochemical models can be made due to the lack of knowledge on large hydrocarbons reactivity.

\section{Discussion}

\section{Low methane consumption}

As carbonitride organic films are known to be absorbent in the UV wavelength range (Khare et al. 1984; Mahjoub et al. 2012), their deposition on the cell windows would involve a darkening of the windows in the UV range. This could explain the lower methane photolysis observed experimentally compared to the predicted total consumption. Such a film deposition is moreover consistent with the fact that photochemistry occurs very close to the window. The calculation of the optical depth at 
Table 4 Species detected by GC-MS and specific of the irradiated cells. For quantitative cross-comparison, peak areas are normalized by the pressure $P 2$ injected in the GC and are therefore given per pressure unit

\begin{tabular}{|c|c|c|c|c|c|c|}
\hline \multirow[b]{3}{*}{ Molecule } & \multirow[b]{3}{*}{ Number on Fig. 5} & \multirow[b]{3}{*}{ Retention time (min) } & \multicolumn{4}{|c|}{ Peak area $\mathrm{hPa}^{-1}$ for every irradiated cells } \\
\hline & & & \multicolumn{2}{|l|}{ Titan 1} & \multicolumn{2}{|l|}{ Titan 2} \\
\hline & & & CF020 & CF041 & $\mathrm{CF} 014$ & CF019 \\
\hline $\mathrm{C}_{2} \mathrm{H}_{6}$ & 1 & 9.6 & 45086 & 55619 & 15164 & 42580 \\
\hline $\mathrm{C}_{3} \mathrm{H}_{8}$ & 2 & 14.7 & 12120 & 14090 & 4026 & 11324 \\
\hline Isobutane & 3 & 18.3 & 3466 & 4790 & 1046 & 3222 \\
\hline $\mathrm{C}_{4} \mathrm{H}_{10}$ & 4 & 19.2 & 3734 & 3282 & 822 & 2365 \\
\hline $\mathrm{C}_{5} \mathrm{H}_{12}$ & 5 & 22.3 & 571 & 671 & 153 & 393 \\
\hline
\end{tabular}
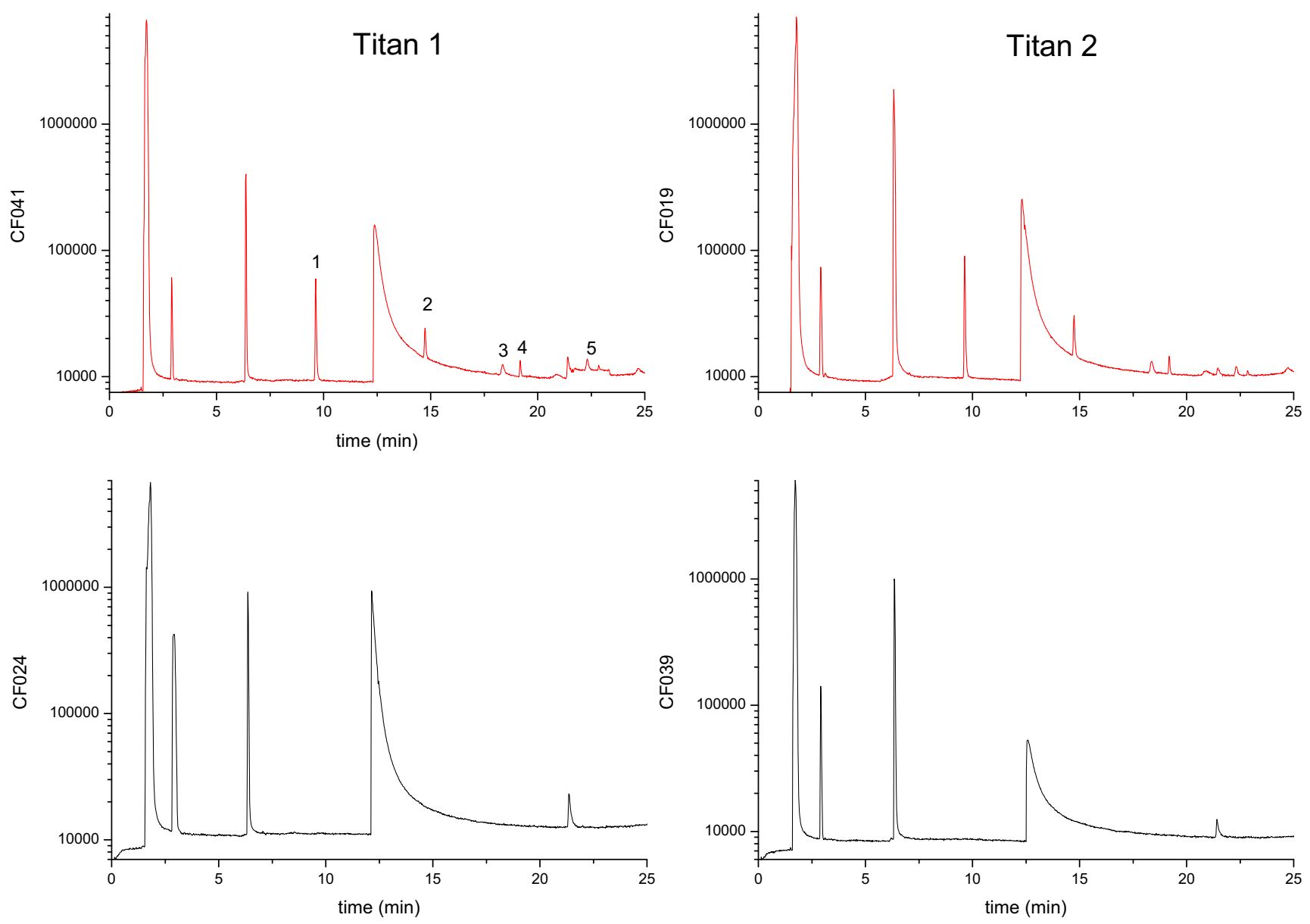

Fig. 6. Total ion current chromatograms obtained in the different cases onboard Expose-Amino: left and right columns are respectively for Titan 1 and 2 cases; upper and lower rows are for the irradiated and non-irradiated cells. Five clear species appear only in the case of irradiated cells, numbered from 1 to 5 on the top left subfigure.

Lyman- $\alpha$ in the cells confirms that the irradiated layer is no thicker than $100 \mu \mathrm{m}$ (Fig. 9).

Photoproducts in the amino experiment compared to Titan's and Saturn's atmospheric compositions

The CIRS instrument onboard the Cassini orbiter is a composite IR spectrometer, which has provided accurate measurements of hydrocarbon abundances in the Saturn system (Flasar et al. 2004). For comparison purpose, the altitude level of
$1 \mathrm{hPa}$, representative of the lower stratosphere of Titan and Saturn is chosen as a reference. Hydrocarbons concentrations are higher in absolute values in Titan's than in Saturn's stratosphere, as methane concentration is about five times higher in the Titan case (Flasar et al. 2004). The hydrocarbon concentrations have therefore to be compared in relative values. At the $1 \mathrm{hPa}$ level, the ratio $\mathrm{C}_{2} \mathrm{H}_{6} / \mathrm{C}_{3} \mathrm{H}_{8}$ is found to be in the range 10-20 for Titan and 20-500 for Saturn, depending on the latitude (Guerlet et al. 2009; Vinatier et al. 2010). In planetary 
Table 5. Ionization cross sections (in $\mathrm{cm}^{-2}$ ) by electron impact at $70 \mathrm{eV}$ for $\mathrm{C}_{2} \mathrm{H}_{6}, \mathrm{C}_{3} \mathrm{H}_{8}, \mathrm{C}_{4} \mathrm{H}_{10}$ and $\mathrm{C}_{5} \mathrm{H}_{12}$. Model 1 by Fitch and Sauter (Fitch \& Sauter 1983) and Model 2 by Hwang et al. (1996). ND: not determined

\begin{tabular}{llll}
\hline & Experimental values & Model 1 & Model 2 \\
\hline $\mathrm{CH}_{4}$ & $3.93 \mathrm{E}-16$ & $4.43 \mathrm{E}-16$ & $3.52 \mathrm{E}-16$ \\
$\mathrm{C}_{2} \mathrm{H}_{6}$ & $6.93 \mathrm{E}-16$ & $7.32 \mathrm{E}-16$ & $6.42 \mathrm{E}-16$ \\
$\mathrm{C}_{3} \mathrm{H}_{8}$ & $1.01 \mathrm{E}-15$ & $1.02 \mathrm{E}-15$ & $8.62 \mathrm{E}-16$ \\
$\mathrm{C}_{4} \mathrm{H}_{10}$ & $1.17 \mathrm{E}-15$ & $1.31 \mathrm{E}-15$ & ND \\
$\mathrm{C}_{5} \mathrm{H}_{12}$ & ND & $1.60 \mathrm{E}-15$ & ND \\
\hline
\end{tabular}

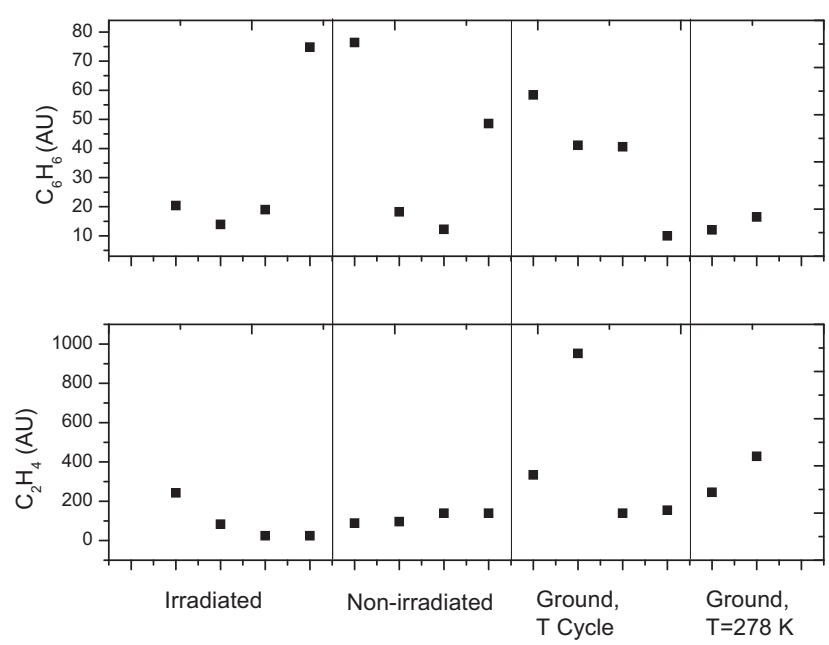

Fig. 7. Concentrations of $\mathrm{C}_{2} \mathrm{H}_{4}$ and $\mathrm{C}_{6} \mathrm{H}_{6}$ in arbitrary unit detected in the cells by $\mathrm{GC}-\mathrm{MS}$ (peaks area per pressure unit).

atmospheres, hydrocarbon abundances are driven simultaneously by photochemistry and transport, and at $1 \mathrm{hPa}$, $\mathrm{C}_{3} \mathrm{H}_{8}$ is more easily photolysed than $\mathrm{C}_{2} \mathrm{H}_{6}$, which is mainly dominated by transport. We could therefore first conclude that the coupling between chemistry and transport increases the $\mathrm{C}_{2} \mathrm{H}_{6} / \mathrm{C}_{3} \mathrm{H}_{8}$ compared to the sole photochemistry experiment of the AMINO-cells (ratio of only $\sim 5$ ). The AMINO value could be seen as a first benchmark for prediction of large saturated hydrocarbons on the sole reactivity criterion. Nevertheless, another parameter, here the pressure, is central for atmospheric reactivity, and could significantly influence the trend between hydrocarbons concentrations observed in the present campaign. The stratospheric concentrations in Titan and Saturn were taken at $1 \mathrm{hPa}$, whereas the AMINO experiments were led at $1500 \mathrm{hPa}$. The higher pressure in our experiment favours termolecular reactions, and explains in particular the dominance of $\mathrm{C}_{2} \mathrm{H}_{6}$ compared with $\mathrm{C}_{2} \mathrm{H}_{2}$ in the AMINO-cells. The effect of a lower pressure would be a major parameter to explore in future campaigns to study the evolution of this first trend found at a given pressure.

\section{Conclusions}

The EXPOSE-AMINO results fully validate the manufacturing process of the new closed cells compared with the EXPOSE-PROCESS campaign.

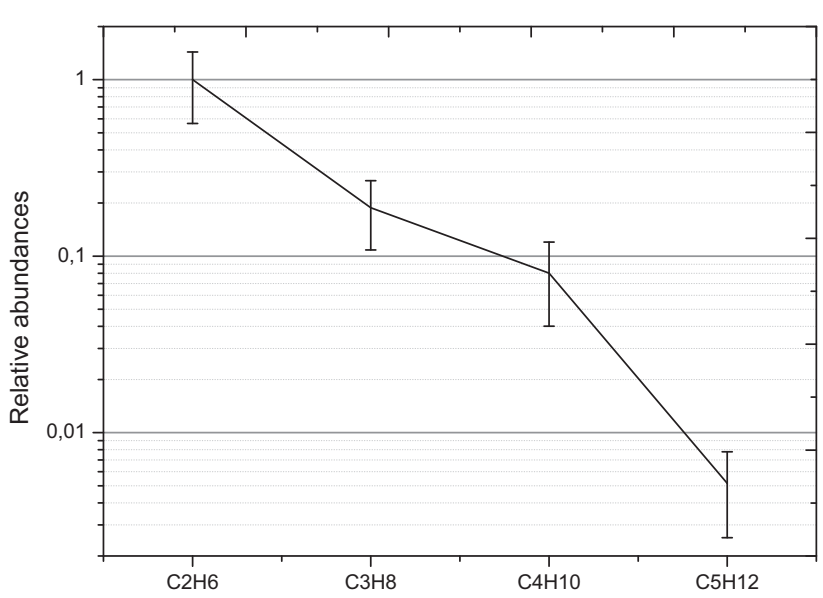

Fig. 8. Saturated hydrocarbons abundances relative to the $\mathrm{C}_{2} \mathrm{H}_{6}$ one.

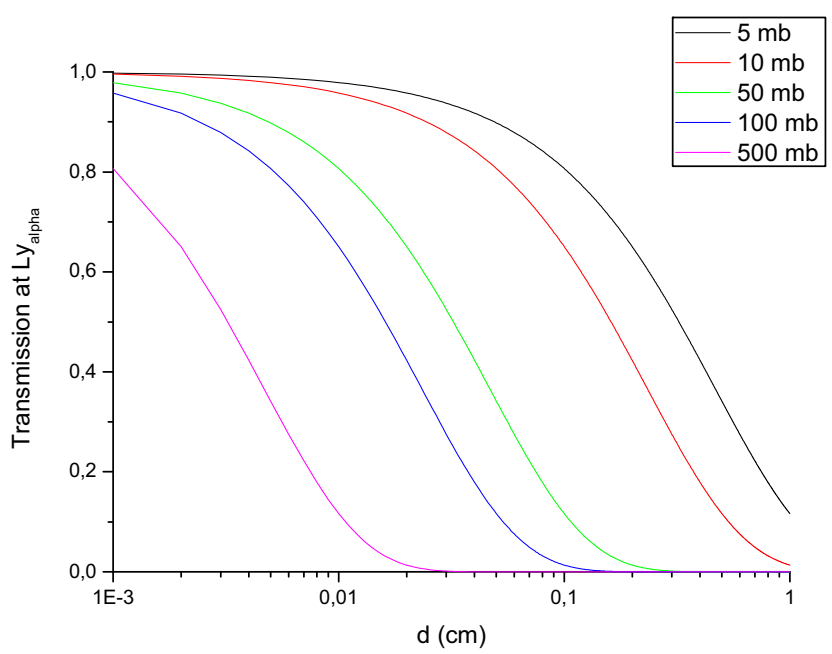

Fig. 9. Theoretical penetration of the Lyman- $\alpha$ Solar component in the cells filled with a methane partial pressure varying from 5 to 500 mbar (500 mbar in the AMINO-cells. See Table 1).

We provide a first consistent reproducible study of the whole methane photolytic chain in space conditions: low temperature and realistic VUV Solar irradiation. Methane is consumed by about $20 \%$ in the four exposed cells, with no influence of $\mathrm{CO}_{2}$. This consumption value is surprisingly low compared to the calculated methane lifetime in the cells. A possible explanation is found in the detection of a solid organic signature formed on the windows of the exposed cells, compatible with the signature of Titan's tholins. Such organic materials have been found to absorb efficiently UV radiation and could therefore explain the passivation observed for methane photolysis.

The gas-phase products detected in the present study are in agreement with the first qualitative analysis made during the EXPOSE-PROCESS campaign, showing a prevalence of saturated hydrocarbons: $\mathrm{C}_{2} \mathrm{H}_{6}, \mathrm{C}_{3} \mathrm{H}_{8}, \mathrm{C}_{4} \mathrm{H}_{10}$ and $\mathrm{C}_{5} \mathrm{H}_{12}$. Their relative abundances have been quantified, showing a clear trend among the species: when increasing the hydrocarbon by one $\mathrm{CH}_{2}$ unit, the concentration of the larger $\mathrm{HC}$ is divided by about a factor of five. The two first hydrocarbons of the series 
were also detected in Titan's and Saturn's atmospheres. The higher $\mathrm{C}_{2} \mathrm{H}_{6} / \mathrm{C}_{3} \mathrm{H}_{8}$ ratios in the planetary systems are in agreement with the transport effect. The AMINO-experiments were not able to simulate the significant production of unsaturated species detected in Titan's atmosphere such as ethylene $\mathrm{C}_{2} \mathrm{H}_{4}$, acetylene $\mathrm{C}_{2} \mathrm{H}_{2}$ and benzene $\mathrm{C}_{6} \mathrm{H}_{6}$. This deviation is explained by the higher pressure used in the AMINOexperiment $\left(1.5 \times 10^{5} \mathrm{~Pa}\right)$, compared to Titan's stratosphere $(0.1-100 \mathrm{hPa})$. Further methane photolysis experiments in space at lower pressures would enable to better simulate the production of the unsaturated photoproducts and to further study the quantitative trend found for the saturated species.

\section{Acknowledgements}

This study was supported by the Centre National d'Etudes Spatiales (CNES). It is based on observations with the AMINO experiment embarked on the EXPOSE-R ESA facility. The authors would like to acknowledge the support of Michel Viso from CNES for the human, financial and technical support; ESA, DLR Cologne (Elke Rabbow and Corinna Panitz); Air Liquide DTA Grenoble (Sébastien Triqueneau), RUAG, Kayser-Threde and RedShift companies.

\section{References}

Bertrand, M., Chabin, A., Colas, C., Cadène, M., Chaput, D., Brack, A., Cottin, H. \& Westall, F. (Submitted). The AMINO experiment: exposure of amino acids in the Expose-R experiment on the International Space Science and in laboratory. Int. J. Astrobiol.

Beuselinck, T. \& Van Bavinchove, C. (2011). EXPOSE: Environmental history by calculation: EXPOSE-R Simulation Results. EXP-RP-020-RS, Issue A, Revision 1. REDSHIFT.

Chen, F.Z. \& Wu, C.Y.R. (2004). Temperature-dependent photoabsorption cross sections in the VUV-UV region. I. Methane and ethane. J. Quant. Spectrosc. Radiat. Transf. 85, 195-209.

Cottin, H. et al. (2008). Heterogeneous solid/gas chemistry of organic compounds related to comets, meteorites, Titan and Mars: in laboratory and in lower Earth orbit experiments. Adv. Space Res. 42, 2019-2035.

Cottin, H. et al. (2012). The PROCESS experiment: an astrochemistry laboratory for solid and gaseous organic samples in low-earth orbit. Astrobiology 12, 412-425.

Coustenis, A. et al. (2007). The composition of Titan's stratosphere from Cassini/CIRS mid-infrared spectra. Icarus 189, 35-62.

Encrenaz, T. (2005). Neutral atmospheres of the giant planets: an overview of composition measurements. Space Sci. Rev. 116, 99-119.

Fitch, W.L. \& Sauter, A.D. (1983). Calculation of relative electron impact total ionization cross sections for organic molecules. Anal. Chem. $\mathbf{5 5}, 832-835$.

Flasar, F.M. et al. (2004). Exploring the Saturn system in the thermal infrared: the composite infrared spectrometer. Space Sci. Rev. 115, 169-297.

Gans, B. et al. (2010). Determination of the absolute photoionization cross sections of $\mathrm{CH}_{3}$ and I produced from a pyrolysis source, by combined synchrotron and vacuum ultraviolet laser studies. J. Phys. Chem. A 114, 3237-3246

Gans, B., Peng, Z., Carrasco, N., Gauyacq, D., Lebonnois, S. \& Pernot, P. (2013). Impact of a new wavelength-dependent representation of methane photolysis branching ratios on the modeling of Titan's atmospheric photochemistry. Icarus 223, 330-343.
Gautier, T., Carrasco, N., Mahjoub, A., Vinatier, S., Giuliani, A., Szopa, C., Anderson, C.M., Correia, J.-J., Dumas, P. \& Cernogora, G. (2012). Mid- and far-infrared absorption spectroscopy of Titan's aerosols analogues. Icarus 221, 320-327.

Guerlet, S., Fouchet, T., Bézard, B., Simon-Miller, A.A. \& Michael Flasar, F. (2009). Vertical and meridional distribution of ethane, acetylene and propane in Saturn's stratosphere from CIRS/Cassini limb observations. Icarus 203, 214-232.

Hwang, W., Kim, Y.K. \& Rudd, M.E. (1996). New model for electronimpact ionization cross sections of molecules. J. Chem. Phys. 104, 2956-2966.

Jacquinet-Husson, N. et al. (2011). The 2009 edition of the GEISA spectroscopic database. J. Quant. Spectrosc. Radiat. Transf. 112, 2395-2445.

Jiao, C.Q., Dejoseph, C.A. Jr. \& Garscadden, A. (2007). Electron impact ionization and ion reactions in n-butane. J. Phys. D: Appl. Phys. 40, 409.

Khare, B.N., Sagan, C., Arakawa, E.T., Suits, F., Callcott, T.A. \& Williams, M.W. (1984). Optical constants of organic tholins produced in a simulated Titanian atmosphere: from soft $x$-ray to microwave frequencies. Icarus $\mathbf{6 0}, 127-137$.

Mahjoub, A., Carrasco, N., Dahoo, P.-R., Gautier, T., Szopa, C. \& Cernogora, G. (2012). Influence of methane concentration on the optical indices of Titan's aerosols analogues. Icarus 221, 670-677.

Nishimura, H. \& Tawara, H. (1994). Total electron impact ionization cross sections for simple hydrocarbon molecules. J. Phys. B: At. Mol. Opt. Phys. 27, 2063.

Peng, Z., Carrasco, N. \& Pernot, P. (2014). Modeling of synchrotron-based laboratory simulations of Titan's ionospheric photochemistry. GeoResJ 1-2, 33-53.

Rabbow, E. et al. (2014). The astrobiological mission EXPOSE-R on board of the International Space Station. Int. J. Astrobiol., this issue.

Raulin, F. \& Bruston, P. (1996). Photochemical growing of complex organics in planetary atmospheres. Adv. Space Res. 18, 41-49.

Rebbert, R.E. \& Ausloos, P. (1972). Photolysis of methane: quantum yield of $\mathrm{C}(1 \mathrm{D})$ and CH. J. Photochem. 1, 171-176.

Romanzin, C., Bénilan, Y., Jolly, A. \& Gazeau, M.C. (2008). Photolytic behaviour of methane at Lyman- $\alpha$ and $248 \mathrm{~nm}$ : studies in the frame of a simulation program of Titan's atmosphere (S.E.T.U.P.). Adv. Space Res. 42, 2036-2044.

Teanby, N.A. et al. (2007). Vertical profiles of $\mathrm{HCN}, \mathrm{HC}_{3} \mathrm{~N}$, and $\mathrm{C}_{2} \mathrm{H}_{2}$ in Titan's atmosphere derived from Cassini/CIRS data. Icarus 186, 364-384.

Thuillier, G., Floyd, L., Woods, T.N., Cebula, R., Hilsenrath, E., Hersé, M. \& Labs, D. (2004). Solar irradiance reference spectra for two solar active levels. Adv. Space Res. 34, 256-261.

Trainer, M.G., Jimenez, J.L., Yung, Y.L., Toon, O.B. \& Tolbert, M.A. (2012). Nitrogen incorporation in $\mathrm{CH}(4)-\mathrm{N}(2)$ photochemical aerosol produced by far ultraviolet irradiation. Astrobiology 12, 315-26.

Venot, O., Fray, N., Bénilan, Y., Gazeau, M.-C., Hébrard, E., Larcher, G., Schwell, M., Dobrijevic, M. \& Selsis, F. (2013). High-temperature measurements of VUV-absorption cross sections of $\mathrm{CO} 2$ and their application to exoplanets. Astron. Astrophys. 551, A131.

Vergne, J., Cottin, H., Silva, L.D., Brack, A., Chaput, D. \& Maurel, M.-C. (submitted). The AMINO experiment: RNA stability under solar radiations on the EXPOSE-R facility of the International Space Station. Int. J. Astrobiol.

Vinatier, S. et al. (2010). Analysis of Cassini/CIRS limb spectra of Titan acquired during the nominal mission: I. Hydrocarbons, nitriles and $\mathrm{CO} 2$ vertical mixing ratio profiles. Icarus 205, 559-570.

Waite, J.H. Jr et al. (2005). Ion neutral mass spectrometer results from the first flyby of Titan. Science 308, 982-986.

Yoshino, K., Esmond, J.R., Sun, Y., Parkinson, W.H., Ito, K. \& Matsui, T. (1996). Absorption cross section measurements of carbon dioxide in the wavelength region 118.7-175.5 $\mathrm{nm}$ and the temperature dependence. J. Quant. Spectrosc. Radiat. Transf. 55, 53-60. 